\title{
Artichoke By-Products as Natural Source of Phenolic Food Ingredient
}

\author{
Lucía López-Salas ${ }^{1}$, Isabel Borrás-Linares ${ }^{2, *}$, David Quintin ${ }^{3}$, Presentación García-Gomez ${ }^{3}$, \\ Rafael Giménez-Martínez ${ }^{1}$, Antonio Segura-Carretero ${ }^{2,4,+}$ and Jesús Lozano-Sánchez ${ }^{1,2,+}{ }^{\text {[D }}$ \\ 1 Department of Food Science and Nutrition, Campus Universitario s/n, University of Granada, \\ 18071 Granada, Spain; 1slucia@correo.ugr.es (L.L.-S.); rafaelg@ugr.es (R.G.-M.); jesusls@ugr.es (J.L.-S.) \\ 2 Functional Food Research and Development Centre (CIDAF), Health Sciencie Technological Park, \\ Avda. Del Conocimiento S/N, 18016 Granada, Spain; ansegura@cidaf.es \\ 3 Centro Tecnológico Nacional de la Conserva y Alimentación, Concordia, s/n, 30500 Molina de Segura, Spain; \\ dquintin@ctnc.es (D.Q.); sese@ctnc.es (P.G.-G.) \\ 4 Department of Analytical Chemistry, Faculty of Sciences, University of Granada, 18071 Granada, Spain \\ * Correspondence: iborras@cidaf.es; Tel.: +34-958-637-083 \\ + These authors are joint senior authors on this work.
}

check for

updates

Citation: López-Salas, L.; Borrás-

Linares, I.; Quintin, D.; García-

Gomez, P.; Giménez-Martínez, R.;

Segura-Carretero, A.; Lozano-

Sánchez, J. Artichoke By-Products as Natural Source of Phenolic Food

Ingredient. Appl. Sci. 2021, 11, 3788.

https://doi.org/10.3390/app11093788

Academic Editors: Luca Mazzoni and Hari Prasad Devkota

Received: 13 March 2021

Accepted: 19 April 2021

Published: 22 April 2021

Publisher's Note: MDPI stays neutral with regard to jurisdictional claims in published maps and institutional affiliations.

Copyright: (c) 2021 by the authors. Licensee MDPI, Basel, Switzerland. This article is an open access article distributed under the terms and conditions of the Creative Commons Attribution (CC BY) license (https:/ / creativecommons.org/licenses/by/ $4.0 /)$.
Abstract: Nowadays, the transformation activity of the food industry results in the generation of a huge amount of daily discarded vegetables wastes. One of those undervalued by-products are produced during the post-harvesting and processing process of artichokes. In the present research, the potential of artichokes' bracts and stalks have been evaluated as a natural source of phenolic compounds which could be used as bioactive food ingredients, among others. In this study, the bioactive composition of those wastes has been evaluated using recent advances in extraction and analytical technologies, concretely, pressurized liquid extraction (PLE) followed by high-performance liquid chromatography (HPLC) coupled to electrospray time-of flight mass spectrometry (ESI-TOF/MS) analysis. To achieve this goal, first, the extraction process was evaluated by a comparative study using GRAS (Generally Recognized As Safe) solvents (mixtures of ethanol and water) at different temperatures $\left(40-200^{\circ} \mathrm{C}\right)$. The second step was to deeply characterize the composition of individual polyphenols by HPLC-ESI-TOF/MS in order to establish a comparison among the different PLE conditions applied to extract the phenolic fraction. The analysis revealed a wide variety of phenolic-composition, mainly phenolic acids and flavonoids. The results also highlighted that high percentages of ethanol and medium-high temperatures pointed out to be useful PLE conditions for recovering this kind of phytochemicals, which could be used in different applications, such as functional food ingredients, cosmetics, or nutraceuticals.

Keywords: artichoke by-products; phenolic compounds; HPLC-ESI-TOF-MS; PLE; GRAS

\section{Introduction}

Nowadays, consumption of fruit and vegetable is very widespread as they provide health benefits. These benefits are partly due to the phenolic compounds that products contain. Phenolic compounds are plant secondary metabolites, with a structure composed of an aromatic ring linked to one or more hydroxyl substitutes. They are synthesized in the normal plant growth and reproduction and, also, during stress conditions such as high temperatures, hydric stress, ultraviolet radiation, or parasites [1]. These phytochemicals are bioactive molecules with antioxidant, antithrombotic, anti-inflammatory, and antidiabetic properties, among others [2-4]. Among phenolic compounds, simple phenols and polyphenols can be distinguished. The first group includes phenolic acids (benzoic and cinnamic acids) and benzoquinones, while flavonoids, stilbenes, lignans, tannins, and other polymerized compounds are part of polyphenols group.

The current need of a sustainable food chain demands an implementation of a circular economy approach in the processing industries. The major focus of this approach is 
to revalorize the discarding parts of vegetables due to their great contents in bioactive compounds. This trend is supported by the potential of these food wastes, which could be used for the production of valued products. In fact, peels, seeds, stems, or vegetable pulps are considered raw materials to obtain bioactive ingredients with multiple applications, mainly for the production of food ingredients, cosmetics, or nutraceuticals. Furthermore, bioactive compounds of vegetable wastes have demonstrated antioxidant and antimicrobial actions in developed food additives used for conservative purposes. Its formulation in nutraceuticals with different presentations, such as syrups, capsules, pills or tablets, is very common $[5,6]$. These applications are possible due to the content in phytochemicals of these vegetable wastes with potent bioactive activities, such as phenolic compounds.

Artichoke (Cynara scolymus L.) is an herbaceous perennial plant belonging to Cynara genus and Asteraceae family. Commonly known as globe artichoke, it is traditionally consumed in the Mediterranean diet in different popular preparations. It can be consumed fresh, canned, roasted, or baked, among others. Therefore, this vegetable is extensively cultivated in Mediterranean countries such as Italy, France, Spain, Egypt, and Morocco. Their cultivation is considered an important activity of the agro-economy of these countries [7,8], indeed, the Mediterranean region has an annual production of about 770,000 tons. The edible portion of this plant includes the receptacle of immature flowers and the inner bracts, named "capitula" or heads. During the artichoke processing, the residues, principally external leaves or stems, represent approximately $60-80 \%$ of the total harvested plant material, which is translated in more than 460,000 tons of wastes generated annually. Nevertheless, these by-products possess a great content of bioactive phenolic compounds, inulin, fibers, and minerals [9-13]. This information highlighted the significance of the evaluation of artichoke wastes for the extraction of bioactive compounds.

The artichoke is one of the most consumed plants of its genus due to its high nutritional value, being rich in water, minerals, vitamins, and carotenoids. Despite its content in these interesting compounds, it is the presence of bioactive compounds that has aroused greater interest, especially phenolic compounds $[14,15]$. The interest in their phytochemicals has been linked to various pharmacological activities exerted on humans. Thus, hepatoprotective, antioxidant, hypocholesterolemic, anticarcinogenic, antibacterial, or diuretic effects have been described for artichoke. Therefore, the artichoke has been used for medicinal purposes since antiquity, being considered a functional food $[9,10,16,17]$.

Consequently, the re-valorization of food by-products as a bioactive source material has experienced a great growth due to the economic and environmental benefits that it produces. In the case of artichoke, recent studies based their research on external bracts, leaves and floral stems by-products, which are considered the principal discarding parts of the artichoke processing because they are not suitable for human consumption [18].

The main objective of this article was to explore the potential of artichoke by-products generated in the food industry as a green and efficient source of phytochemicals with many applications. For this purpose, the present research optimized the extraction of the phenolic profile from artichoke bracts and stems, which were obtained as industrial by-products, through an advanced extraction system and characterized the composition of the obtained extracts by a powerful analytical platform. Thus, pressurized liquid extraction (PLE) using water and ethanol as GRAS extraction solvents was chosen due to its great potential to extract phenolic compounds in green and efficient processes from vegetable matrices. Similarly, reversed-phase high-performance liquid chromatography coupled to electrospray time-of-flight mass spectrometry (HPLC-ESI-TOF-MS) was selected for the analytical characterization of the PLE extracts due to its great potential.

\section{Materials and Methods}

2.1. Reagents

The chemicals employed during the development of this study have analytical reagent grade. Purified water used for extraction and analytical experiments was obtained from a Milli-Q system from Millipore (Bedford, MA, USA). Moreover, ethanol used to obtain 
artichoke PLE extracts was purchased from VWR Chemicals (Radnor, PA, USA), whereas sand and cellulose filters were from Fisher Chemicals (Waltham, MA, USA). The mobile phases used for the analysis were prepared with formic acid and LC-MS-grade methanol provided from Sigma-Aldrich (Steinheim, Germany) and Fisher Chemicals (Waltham, MA, USA), respectively.

\subsection{Plant Material}

By-products such as bracts and stems were obtained from the industrial processing of artichokes. The post-harvest processing of artichokes consists in a minimally blanching step carried out in the same day of harvesting before peeling. This processing was performed with water for $20 \mathrm{~min}$ at $98^{\circ} \mathrm{C}$. After blanching, the artichokes were pealed and the bracts and stems were separated from the artichoke hearts. These by-products were frozen at $-45{ }^{\circ} \mathrm{C}$ and lyophilized for $24 \mathrm{~h}$ in a freeze-dryer (Vertis SP Scientific, Thermo Fisher (Madrid, Spain).

\subsection{Pressurized Liquid Extraction}

PLE extracts from artichoke by-products were obtained with an accelerated solvent extractor (ASE 350, Dionex, Sunnyvale, CA, USA) applying different combinations of temperature and solvent composition (mixtures of ethanol and water in different proportions) previously applied to food by-products. These conditions were selected to cover a wide range of dielectric constant (from 19 to 59.1) [19,20].

Briefly, PLE static extractions were performed during 20 min under a pressure of $1500 \mathrm{psi}$. Thus, the tested ranges of instrumental parameters were as follow: $0-100 \%$ of aqueous ethanol mixtures as extraction solvent and 40 to $200^{\circ} \mathrm{C}$ as extraction temperature.

The experiments were performed with extraction cells of $33 \mathrm{~mL}$ filled with a homogenous mixture composed of $4 \mathrm{~g}$ of artichoke sample plus $8 \mathrm{~g}$ of sand. This sample-sand ratio $(1: 2, \mathrm{w}: \mathrm{w})$ allows to perform the experiments avoiding technical problems (fundamentally blockage of the lines of the PLE instrument) with the maximum amount of sample. The solvents used in each PLE experiment were previously sonicated for $15 \mathrm{~min}$ in order to eliminate the oxygen dissolved in the mixture, which could provoke a degradation of compounds susceptible of oxidation.

The PLE process begins with a cell heat-up step previous to the extraction in order to attain the pertinent extraction temperature. The duration of this phase is dependent of the temperature set-point and established by the instrument (lasting from 5 to $9 \mathrm{~min}$ ). Then, the extraction step was carried out applying the corresponding conditions according to Table 1.

Table 1. Experimental pressurized liquid extraction (PLE) conditions.

\begin{tabular}{|c|c|c|}
\hline Experimental Condition & $\begin{array}{l}\text { Temperature and Percentage of } \\
\text { Ethanol in the Extraction Solvent }\end{array}$ & Dielectric Constant \\
\hline PLE 1 & $120{ }^{\circ} \mathrm{C} ; \mathrm{EtOH} 100 \%$ & 19.0 \\
\hline PLE 2 & $176^{\circ} \mathrm{C} ; \mathrm{EtOH} 85 \%$ & 21.6 \\
\hline PLE 3 & $200^{\circ} \mathrm{C} ; \mathrm{EtOH} 50 \%$ & 26.0 \\
\hline PLE 4 & $63{ }^{\circ} \mathrm{C} ; \mathrm{EtOH} 85 \%$ & 31.0 \\
\hline PLE 5 & $176^{\circ} \mathrm{C} ; \mathrm{EtOH} 15 \%$ & 33.4 \\
\hline PLE 6 & $120{ }^{\circ} \mathrm{C} ; \mathrm{EtOH} 50 \%$ & 34.7 \\
\hline PLE 7 & $40{ }^{\circ} \mathrm{C} ; \mathrm{EtOH} 50 \%$ & 48.0 \\
\hline PLE 8 & $120{ }^{\circ} \mathrm{C} ; \mathrm{EtOH} \mathrm{0 \%}$ & 50.4 \\
\hline PLE 9 & $63{ }^{\circ} \mathrm{C} ; \mathrm{EtOH} 15 \%$ & 59.1 \\
\hline
\end{tabular}

The obtained extracts were immediately cooled at room temperature in an ice-bath. The supernatants were separated after a centrifugation step of $15 \mathrm{~min}$ at $4{ }^{\circ} \mathrm{C}$ applying 
12,499 as relative centrifugal force (RCF). Then, they were completely evaporated under vacuum at $35^{\circ} \mathrm{C}$ in a Savan SC250EXP Speed-Vac (Thermo Scientific, Leicestershire, UK). The dry extracts were stored refrigerated $\left(-20^{\circ} \mathrm{C}\right)$ avoiding light exposure until further use.

\subsection{HPLC-ESI-TOF-MS Analysis}

The analysis of the artichoke by-products PLE extracts was carried out by highperformance liquid chromatography (HPLC) with a diode array detector (DAD) coupled to time-of-flight mass spectrometry with an electrospray interface (ESI-TOF-MS). The instrument was an Agilent 1200-RRLC system (Agilent Technologies, Palo Alto, CA, USA) equipped with a vacuum degasser, a binary pump, an auto-sampler, a thermostatically controlled column compartment, and a DAD detector. Mass detection was performed using a micrOTOF II analyzer from Bruker Daltonik (Bremen, Germany). The extracts were dissolved in aqueous ethanol (50:50, v/v) at $5 \mathrm{mg} / \mathrm{mL}$ and analyzed in triplicate. Before the HPLC injection, the samples were filtered through a $0.45 \mu \mathrm{m}$ syringe filters of regenerated cellulose to avoid solid particles.

The separation occurs in an Agilent Zorbax Eclipse Plus C18 column $(150 \mathrm{~mm} \times 4.6 \mathrm{~mm}$ $\mathrm{id}, 1.8 \mu \mathrm{m})$. The mobile phases consist of water with $0.1 \%$ formic acid (A) and methanol (B) at a flow rate of $0.8 \mathrm{~mL} / \mathrm{min}$. The analytical method used an elution gradient according to the following linear multi-step profile: $0 \mathrm{~min}, 5 \% \mathrm{~B} ; 3 \mathrm{~min}, 50 \% \mathrm{~B} ; 25 \mathrm{~min}, 75 \% \mathrm{~B} ; 35 \mathrm{~min}$, $100 \% \mathrm{~B}, 40 \mathrm{~min}$, and $5 \% \mathrm{~B}$ plus $5 \mathrm{~min}$ of stabilization at initial conditions before the next analysis. The analyses were carried out at $25^{\circ} \mathrm{C}$ injecting $10 \mu \mathrm{L}$ of sample in each run.

Detection was performed within a mass range of $50-1000 \mathrm{~m} / \mathrm{z}$ operating in negative ionization mode. In order to achieve a stable ionization, the flow rate from the HPLC was split before the connection to the ESI interface (Agilent Technologies) until $125 \mu \mathrm{L} / \mathrm{min}$. Ultrapure nitrogen was used as drying and nebulizing gas with flows of $9.0 \mathrm{~L} \mathrm{~min}^{-1}$ and 2.0 bar, respectively. The operating parameters applied for the ionization and ion transfer were: capillary voltage of $+4.5 \mathrm{kV}$; drying gas temperature, $190{ }^{\circ} \mathrm{C}$; capillary exit, $-150 \mathrm{~V}$; skimmer 1, -50 V; hexapole 1, -23 V; RF hexapole, $100 \mathrm{Vpp}$; and skimmer 2, -22.5 V.

In order to recalibrate the mass spectra acquired during the analysis to achieve accurate mass measurements with a precision better than $5 \mathrm{ppm}, 10 \mathrm{mM}$ sodium formate solution was used as calibrant. This mixture is automatically injected at the beginning of each run by means of a 74900-00-05 Cole Palmer syringe pump (Vernon Hills, IL, USA) directly connected to the ESI interface, equipped with a Hamilton syringe (Reno, NV, USA). All data acquisition and processing operations were controlled with HyStar 3.2 and Data Analysis 4.0 software, respectively (Bruker Daltonics $\mathrm{GmbH}$, Bremen, Germany). The software provides a list of possible elemental formulas using the Generate-Molecular Formula Editor. This information provided by the analytical platform was used for identification purposes together with the one reported in databases and bibliography.

\subsection{Statistical Analysis}

Data were statistically treated using Origin (Version Origin Pro 8.5, Northampton, MA, USA). For these data, set one-way analysis of variance (ANOVA, Tukey's test) at a $95 \%$ confidence level ( $p \leq 0.05$ ) was performed to point out the differences in semiquantitative bioactive compounds contents found between PLE artichoke samples with statistical significance.

\section{Results}

\subsection{Identification of Phytochemical Compounds of Artichoke By-Products by HPLC-ESI-TOF-MS}

The compounds were identified by the data provided by the HPLC-ESI-TOF-MS instrument. Thus, for all the peaks detected in the chromatogram, a list of possible molecular formulas was obtained with DataAnalysis 4.0 software. The identification was achieved comparing with the data previously reported in databases and literature for artichoke composition.

The bibliography search consulted for the tentative identification of the detected compounds was composed by studies carried out on artichoke. Therefore, one of the 
studies reported the inflorescence of artichoke, which were lyophilized and extracted by ultrasound-assisted extraction (UAE) using $80 \%$ methanol as solvent [21]. Other authors evaluated the phenolic profile of the edible parts of artichokes (receptacle and internal bracts) using a conventional procedure and mixture of solvents, concretely sonication in methanol/water $(70: 30, v / v)[10,22]$. Finally, another study was based on the study of the chemical composition of artichoke by-products (leaves, floral stems, and bracts) applying maceration with $80 \%$ methanol-water mixture able to obtain extracts enriched in polar compounds [18].

Figure 1 shows a representative base peak chromatogram (BPC) of artichoke byproducts PLE extract obtained by HPLC-ESI-TOF-MS analyzed in negative polarity. Moreover, Figure 2 includes the extracted ion chromatograms and mass spectra of the major phenolic compounds characterized in those extracts. Furthermore, Table 2 summarizes the main peaks detected according to their elution order, including the information provided by the MS spectrometer: experimental and theoretical $\mathrm{m} / \mathrm{z}$, error (ppm), molecular formula, proposed compound, and the PLE condition in which each of them was detected. As can be observed, a total of 23 compounds were detected, being 19 of them tentatively identified. Despite the information provided by the analyzer and the effort made for their identification, unfortunately four compounds remain unknown (listed as UK in Table 2). The proposed compounds were tentatively identified as phenolic acids, flavones, and derivatives (flavonoids), saponins, lipids, and other polar compounds. In the following sections, the tentatively identification of these compounds has been described according to these chemical sub-classes.

Table 2. Phenolic and other polar compounds characterized in Cynara scolymus L. PLE extracts analyzed by HPLC-time-offlight mass spectrometry with an electrospray interface (ESI-TOF/MS).

\begin{tabular}{|c|c|c|c|c|c|c|c|}
\hline Peak & $\begin{array}{c}\mathrm{RT} \\
(\mathrm{min})\end{array}$ & Proposed Compound & $\begin{array}{c}\text { Theoretical } \\
\mathrm{m} / \mathrm{z}\end{array}$ & $\begin{array}{l}\text { Experimental } \\
\mathrm{m} / \mathrm{z}\end{array}$ & $\begin{array}{l}\text { Molecular } \\
\text { Formula }\end{array}$ & $\begin{array}{l}\text { Error } \\
(\mathrm{ppm})\end{array}$ & $\begin{array}{c}\text { PLE } \\
\text { Experiment }\end{array}$ \\
\hline 1 & 2.14 & Quinic acid & 191.0561 & 191.0567 & $\mathrm{C}_{7} \mathrm{H}_{12} \mathrm{O}_{6}$ & -3.2 & * \\
\hline 2 & 6.14 & Chlorogenic acid & 353.0878 & 353.0883 & $\mathrm{C}_{16} \mathrm{H}_{18} \mathrm{O}_{9}$ & -1.5 & * \\
\hline 3 & 6.51 & UK 1 & 375.0663 & 375.067 & $\mathrm{C}_{25} \mathrm{H}_{12} \mathrm{O}_{4}$ & -5.4 & $1,2,4,5,6,7,9$ \\
\hline 4 & 6.62 & Rosamarinic acid & 359.0772 & 359.0735 & $\mathrm{C}_{18} \mathrm{H}_{16} \mathrm{O}_{8}$ & 10.5 & $1,4,5,6,7,8,9$ \\
\hline 5 & 7.36 & Cynarin isomer 1 & 515.1195 & 515.1211 & $\mathrm{C}_{25} \mathrm{H}_{24} \mathrm{O}_{12}$ & -4.5 & * \\
\hline 6 & 7.65 & Luteolin-rutinoside & 593.1512 & 593.1514 & $\mathrm{C}_{27} \mathrm{H}_{30} \mathrm{O}_{15}$ & -0.3 & * \\
\hline 7 & 7.95 & Luteolin-glucoside & 447.0933 & 447.0919 & $\mathrm{C}_{21} \mathrm{H}_{20} \mathrm{O}_{11}$ & -4 & * \\
\hline 8 & 8.08 & Cynarin isomer 2 & 515.1195 & 515.1207 & $\mathrm{C}_{25} \mathrm{H}_{24} \mathrm{O}_{12}$ & -2.2 & * \\
\hline 9 & 8.58 & Apigenin-rutinoside & 577.1563 & 577.1571 & $\mathrm{C}_{27} \mathrm{H}_{30} \mathrm{O}_{14}$ & -1.4 & * \\
\hline 10 & 8.98 & Apigenin-glucoside & 431.0984 & 431.0965 & $\mathrm{C}_{21} \mathrm{H}_{20} \mathrm{O}_{10}$ & -3.1 & * \\
\hline 11 & 10.27 & UK 2 & 345.0405 & 345.0374 & $\mathrm{C}_{20} \mathrm{H}_{10} \mathrm{O}_{6}$ & 9 & * \\
\hline 12 & 11.62 & UK 3 & 207.0663 & 207.0657 & $\mathrm{C}_{11} \mathrm{H}_{12} \mathrm{O}_{4}$ & 2.7 & $1,2,3,5,6$ \\
\hline 13 & 13.40 & Luteolin & 285.0405 & 285.0412 & $\mathrm{C}_{15} \mathrm{H}_{10} \mathrm{O}_{6}$ & -2.5 & $1,3,4,5,6,7,8,9$ \\
\hline 14 & 15.95 & Apigenin & 269.0455 & 269.0459 & $\mathrm{C}_{15} \mathrm{H}_{10} \mathrm{O}_{5}$ & -6.8 & * \\
\hline 15 & 20.65 & $\begin{array}{l}\text { Trihydroxy-octadecenoic } \\
\text { acid }\end{array}$ & 329.2333 & 329.2331 & $\mathrm{C}_{18} \mathrm{H}_{34} \mathrm{O}_{5}$ & 0.6 & * \\
\hline 16 & 22.51 & $\begin{array}{c}\text { Dihydroxy-hexadecanoic } \\
\text { acid }\end{array}$ & 287.2228 & 287.2229 & $\mathrm{C}_{16} \mathrm{H}_{32} \mathrm{O}_{4}$ & -0.3 & $1,3,4,5,6,7,8,9$ \\
\hline 17 & 23.15 & Methylapigenin & 283.0612 & 283.0607 & $\mathrm{C}_{16} \mathrm{H}_{12} \mathrm{O}_{5}$ & 1.7 & $1,2,3,4,6$ \\
\hline 18 & 26.62 & $\begin{array}{l}\text { Cynarasaponin } \mathrm{A} / \mathrm{H} \\
\text { isomer }\end{array}$ & 925.4802 & 925.476 & $\mathrm{C}_{47} \mathrm{H}_{74} \mathrm{O}_{18}$ & 4.6 & $1,6,7,9$ \\
\hline
\end{tabular}


Table 2. Cont.

\begin{tabular}{cccccccc}
\hline Peak & $\begin{array}{c}\text { RT } \\
(\mathbf{m i n})\end{array}$ & Proposed Compound & $\begin{array}{c}\text { Theoretical } \\
\mathbf{m} / z\end{array}$ & $\begin{array}{c}\text { Experimental } \\
\mathbf{m} / z\end{array}$ & $\begin{array}{c}\text { Molecular } \\
\text { Formula }\end{array}$ & $\begin{array}{c}\text { Error } \\
\text { (ppm) }\end{array}$ & $\begin{array}{c}\text { PLE } \\
\text { Experiment }\end{array}$ \\
\hline 19 & 26.92 & $\begin{array}{c}\text { Cynarasaponin A/H } \\
\text { isomer }\end{array}$ & 925.4802 & 925.478 & $\mathrm{C}_{47} \mathrm{H}_{74} \mathrm{O}_{18}$ & 2.4 & $1,6,7,9$ \\
\hline 20 & 30.05 & UK 4 & 205.1598 & 205.1606 & $\mathrm{C}_{14} \mathrm{H}_{22} \mathrm{O}$ & -3.8 & $2,3,4,5,6,7,8,9$ \\
\hline 21 & 31.10 & $\begin{array}{c}\text { Hydroxy- } \\
\text { octadecatrienoic } \\
\text { acid }\end{array}$ & 293.2122 & 293.2111 & $\mathrm{C}_{18} \mathrm{H}_{30} \mathrm{O}_{3}$ & 3.9 & $1,2,4,6,7,9$ \\
\hline 22 & 31.27 & $\begin{array}{c}\text { Hydroxy- } \\
\text { octadecadienoic } \\
\text { acid }\end{array}$ & 295.2279 & 295.2286 & $\mathrm{C}_{18} \mathrm{H}_{32} \mathrm{O}_{3}$ & -2.6 \\
\hline 23 & 33.19 & Linolenic acid & 277.2173 & 277.2170 & $\mathrm{C}_{18} \mathrm{H}_{30} \mathrm{O}_{2}$ & 1.1 \\
\hline
\end{tabular}

$\left(^{*}\right)$ Indicate that these compounds were identified in all the PLE extracts. For those compounds that were not identified in all the extracts, the number of the PLE experiment in which they were detected was annotated. UK, unknown.

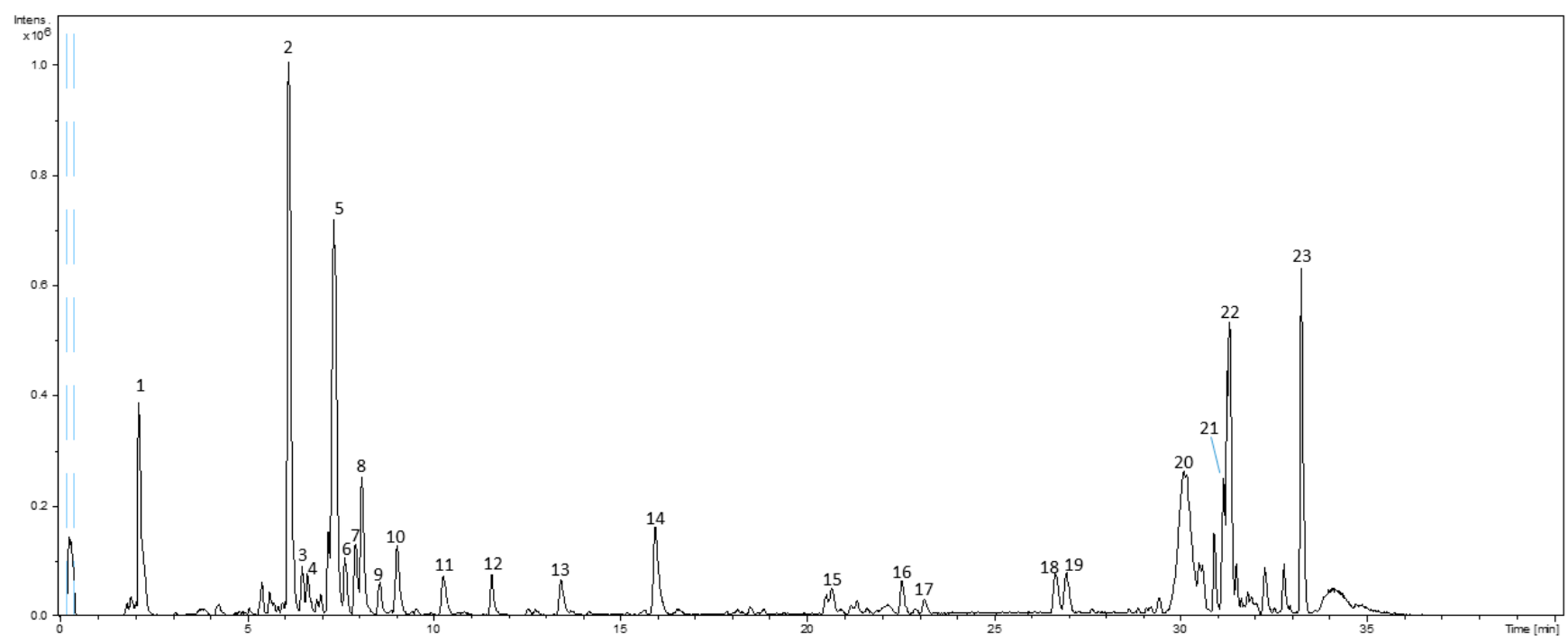

Figure 1. Base peak chromatogram (BPC) of representative pressurized liquid extraction (PLE) extracts of Cynara scolymus L. by-products.

\subsubsection{Phenolic Acids}

Peak 2, with a precursor ion at $m / z 353.0878$ was identified as chlorogenic acid [21], whereas peak 4, with $m / z 359.0772$ and a molecular formula $\mathrm{C}_{18} \mathrm{H}_{16} \mathrm{O}_{8}$, was proposed as rosamarinic acid [22]. Moreover, peaks 5 and 8, which displayed a $m / z 515.1195$ and retention times of 7.36 and $8.08 \mathrm{~min}$, respectively, were identified as cynarin isomers, also named "dicaffeoylquinic acid isomers" [21,22].

\subsubsection{Flavonoids}

With regard to flavonoids and its several sub-classes, only flavones and their derivatives were detected in artichokes by-products. Thereby, peak 6, with $m / z$ at 593.1512, was tentatively identified as luteolin-rutinoside [18], while peak 7 with $\mathrm{m} / \mathrm{z}$ at 447.0933 was proposed as luteolin-glucoside (cymaroside) according to bibliographic data [10,21]. Furthermore, the compound eluting at $8.58 \mathrm{~min}$ (peak 9) and displaying $\mathrm{m} / \mathrm{z} 577.1563$ was considered as apigenin-rutinoside (isorhoifolin) [21]. In the same way, peak 10, detected at $8.98 \mathrm{~min}$ and $\mathrm{m} / \mathrm{z} 431.0984$, was tentatively assigned to apigenin-glucoside according to the comparison of the molecular formula provided by the detector and literature data [21]. Similarly, peak 13 at $m / z 285.0405$ and molecular formula $\mathrm{C}_{15} \mathrm{H}_{10} \mathrm{O}_{6}$ along with peak 14 at $15.44 \mathrm{~min}$ and $\mathrm{m} / \mathrm{z} 269.0455$ were proposed according to the literature as luteolin $[10,21]$ and 
apigenin $[10,21]$, respectively. Finally, peak 17 with $\mathrm{m} / z 283.0612$ was tentatively assigned to methylapigenin [22].

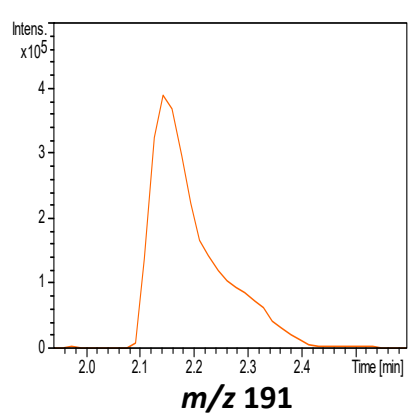

Quinic acid

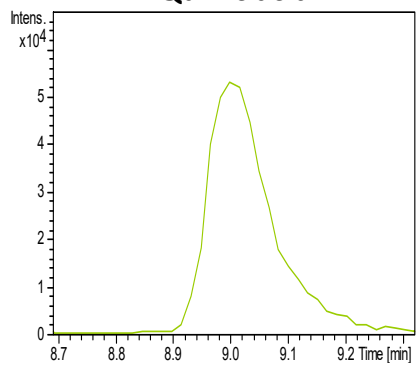

$m / z 431$

Apigenin-7-0-glucoside

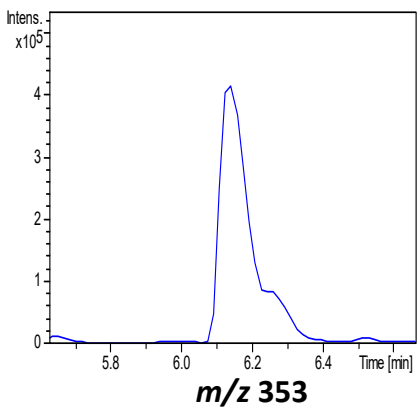

Chlorogenic acid

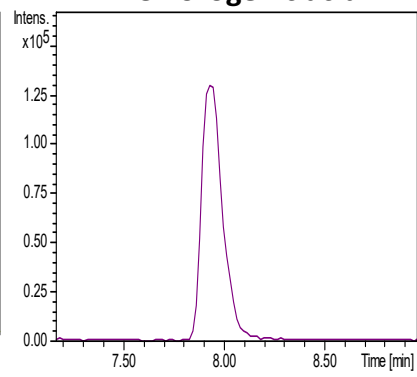

$m / z 447$

Luteolin-7-0-glucoside

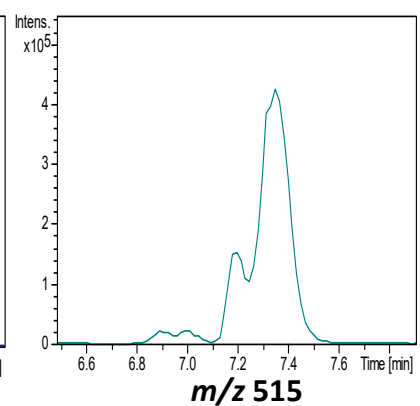

Dicaffeoylquinic acid

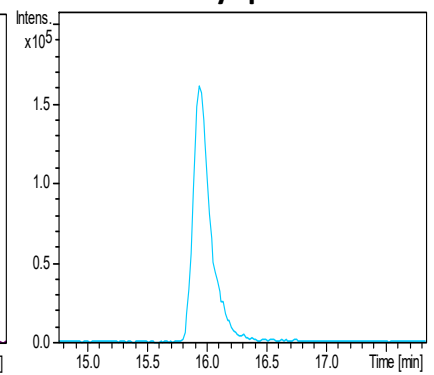

$m / z 269$

Apigenin

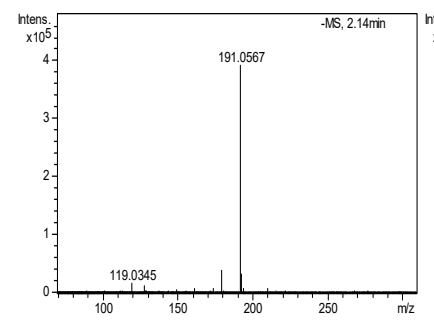

$m / z 191$

Quinic acid

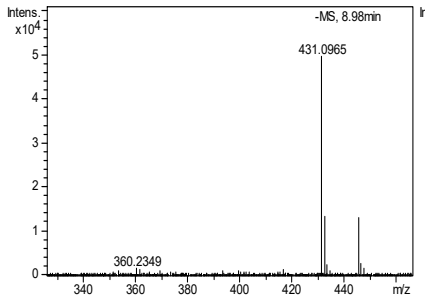

$m / 2431$

Apigenin-7-0-glucoside

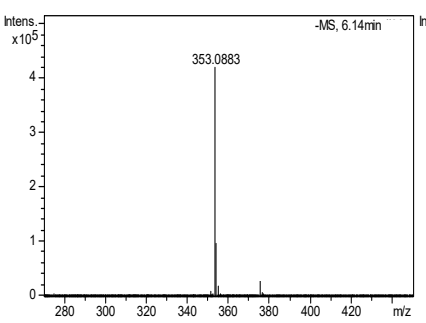

$m / z 353$

Chlorogenic acid

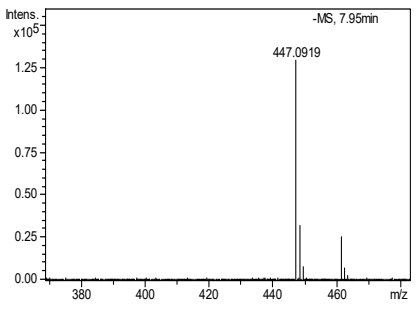

$m / z 447$

Luteolin-7-0-glucoside

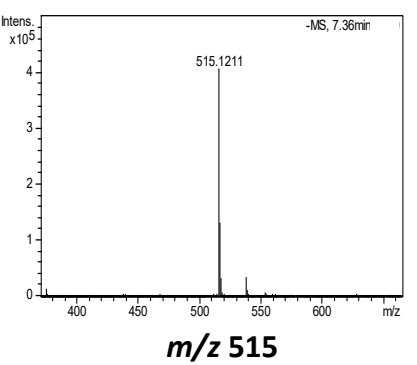

Dicaffeoylquinic acid

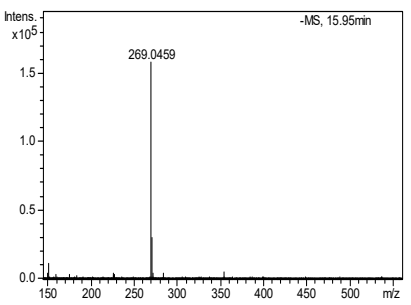

$m / z 269$

Apigenin

Figure 2. Extracted ion chromatograms (EIC) and mass spectra of some phenolic compounds characterized by HPLC-time-of-flight mass spectrometry with an electrospray interface (ESI-TOF/MS) in artichoke by-products.

\subsubsection{Saponins, Lipids, and Other Polar Compounds}

Peak 1 , with $m / z$ at 191.0561, was proposed as quinic acid, a carboxylic acid commonly found in artichoke [21]. 
On the other hand, compounds belonging to saponins family correspond to peaks 18 and 19. They displayed a $\mathrm{m} / \mathrm{z} 925.4802$ and retention times of 26.62 and $26.92 \mathrm{~min}$, respectively. Both were identified as isomers of cynarasaponin $\mathrm{A}$ or $\mathrm{H}$ [21].

Lastly, several lipids were also found in these artichoke samples. Thence, hydroxyoctadecatrienoic acid (peak 21) is a lipid previously identified in artichoke [21]. Trihydroxyoctadecenoic acid (peak 15), hydroxy-octadecadienoic acid (peak 22), and linolenic acid (peak 23) were also detected in the present analysis. All these lipids have been previously identified in other vegetable PLE extracts, such as Morus nigra [23] and Prunus avium [24]. Similarly, dihydroxyhexadecanoic acid (peak 16) was identified in the present study as well as in Symphytum officinale L. samples [25]. Although these plant matrices belong to different species, both molecular formula and $\mathrm{m} / \mathrm{z}$ generated by the software match with data reported in the bibliography.

\subsection{Extraction Yield and Extraction Efficiency}

In this study, different PLE conditions were evaluated and compared in terms of yield and recovery of individual phenolic compounds from artichoke by-products. The extraction yield was expressed as weight of collected extract per dry plant material $(w / w$, in grams) used in the extraction procedure. The extraction efficiency of individual compounds was estimated by a semi-quantitative approach, measuring the peak areas of the compounds identified in the chromatogram as expressed as mean \pm standard deviation of three consecutive injections. Table 3 includes the extraction yield and phenolic extraction efficiency for the $C$. scolymus L. PLE extracts.

Table 3. Extraction yield and phenolic compounds recovery for C. scolymus L. obtained in each PLE condition. Yield (\%), individual phenolic compounds (peak area $\times \mathrm{E}+4$ ). Value $=$ mean \pm standard deviation.

\begin{tabular}{|c|c|c|c|c|c|c|}
\hline $\begin{array}{l}\text { Experimental } \\
\text { Condition }\end{array}$ & $\begin{array}{l}\text { Dielectric } \\
\text { Constant }\end{array}$ & $\begin{array}{l}\text { Extraction } \\
\text { Conditions }\end{array}$ & Yield & $\begin{array}{c}\text { Total } \\
\text { Phenolic Acids }\end{array}$ & $\begin{array}{c}\text { Total } \\
\text { Flavonoids }\end{array}$ & $\begin{array}{c}\text { Total } \\
\text { Phenolic Compounds }\end{array}$ \\
\hline PLE 1 & 19.0 & $\begin{array}{c}120{ }^{\circ} \mathrm{C} ; \mathrm{EtOH} \\
100 \%\end{array}$ & $7.4 \pm 0.3$ & $787 \pm 25$ & $488 \pm 13$ & $1274 \pm 37$ \\
\hline PLE 2 & 21.6 & $176^{\circ} \mathrm{C} ; \mathrm{EtOH} 85 \%$ & $50 \pm 1$ & $190 \pm 10$ & $94.1 \pm 0.3$ & $284 \pm 10$ \\
\hline PLE 3 & 26 & $200{ }^{\circ} \mathrm{C} ; \mathrm{EtOH} 50 \%$ & $57 \pm 2$ & $285 \pm 10$ & $157 \pm 1$ & $442 \pm 10$ \\
\hline PLE 4 & 31.0 & $63^{\circ} \mathrm{C} ; \mathrm{EtOH} 85 \%$ & $10.5 \pm 0.8$ & $728 \pm 24$ & $365 \pm 8$ & $1092 \pm 33$ \\
\hline PLE 5 & 33.4 & $176^{\circ} \mathrm{C} ; \mathrm{EtOH} 15 \%$ & $45 \pm 2$ & $134 \pm 4$ & $43.9 \pm 0.4$ & $178 \pm 4$ \\
\hline PLE 6 & 34.7 & $120{ }^{\circ} \mathrm{C} ; \mathrm{EtOH} 50 \%$ & $40 \pm 2$ & $343 \pm 5$ & $145 \pm 2$ & $489 \pm 4$ \\
\hline PLE 7 & 48.0 & $40^{\circ} \mathrm{C}$; EtOH 50\% & $19 \pm 1$ & $594 \pm 16$ & $253 \pm 16$ & $848 \pm 17$ \\
\hline PLE 8 & 50.4 & $120{ }^{\circ} \mathrm{C} ; \mathrm{EtOH} 0 \%$ & $37 \pm 2$ & $302 \pm 8$ & $66 \pm 1$ & $368 \pm 7$ \\
\hline PLE 9 & 59.1 & $63{ }^{\circ} \mathrm{C} ; \mathrm{EtOH} 15 \%$ & $25 \pm 2$ & $291 \pm 18$ & $75 \pm 4$ & $365 \pm 22$ \\
\hline
\end{tabular}

Concerning the extraction yield, the obtained results in the different PLE experiments are highly inconstant. Similar variations were observed in other PLE extracts from plants such as black mulberry or sweet cherry stems, ranging from $11 \%$ to $48 \%$ or from $3 \%$ to $49 \%$, respectively $[23,25]$. In general, it could be observed that the application of elevated temperatures (above $170^{\circ} \mathrm{C}$ ) resulted in higher extraction yields. Indeed, PLE $3\left(200^{\circ} \mathrm{C}\right.$, $\mathrm{EtOH} 50 \%)$, PLE $2\left(176{ }^{\circ} \mathrm{C}, \mathrm{EtOH} 85 \%\right)$, and PLE $5\left(176^{\circ} \mathrm{C}, \mathrm{EtOH} 15 \%\right)$ were the extraction conditions with the highest yield values ( $57 \pm 2 \%, 50 \pm 1 \%$, and $45 \pm 2 \%$, respectively). This fact could be explained by the increase in solvent diffusivity with increasing temperature, which enhances the extraction of several components from vegetable matrices [26]. In contrast to this observation, it could not establish a relationship between the percentage of ethanol and extraction yield. 
Focusing on the individual recovery of phenolic compounds of each PLE condition, a relationship between the extraction parameters (temperature and percentage of ethanol) and the enhancement extraction of particular compounds could be revealed.

In this sense, regarding phenolic compounds, as described above, both sub-classes of polyphenols (phenolic acids and flavonoids) identified in the samples were extracted under all the PLE experiments. The individual areas of all compounds identified in PLE extracts were also analyzed to evaluate significant differences among the different PLE conditions. Figure 3 draws the peak area (mean value \pm standard deviation) of the individual compounds detected in each artichoke PLE extract as well as the total phenolic acids and flavonoids (see Table S1).
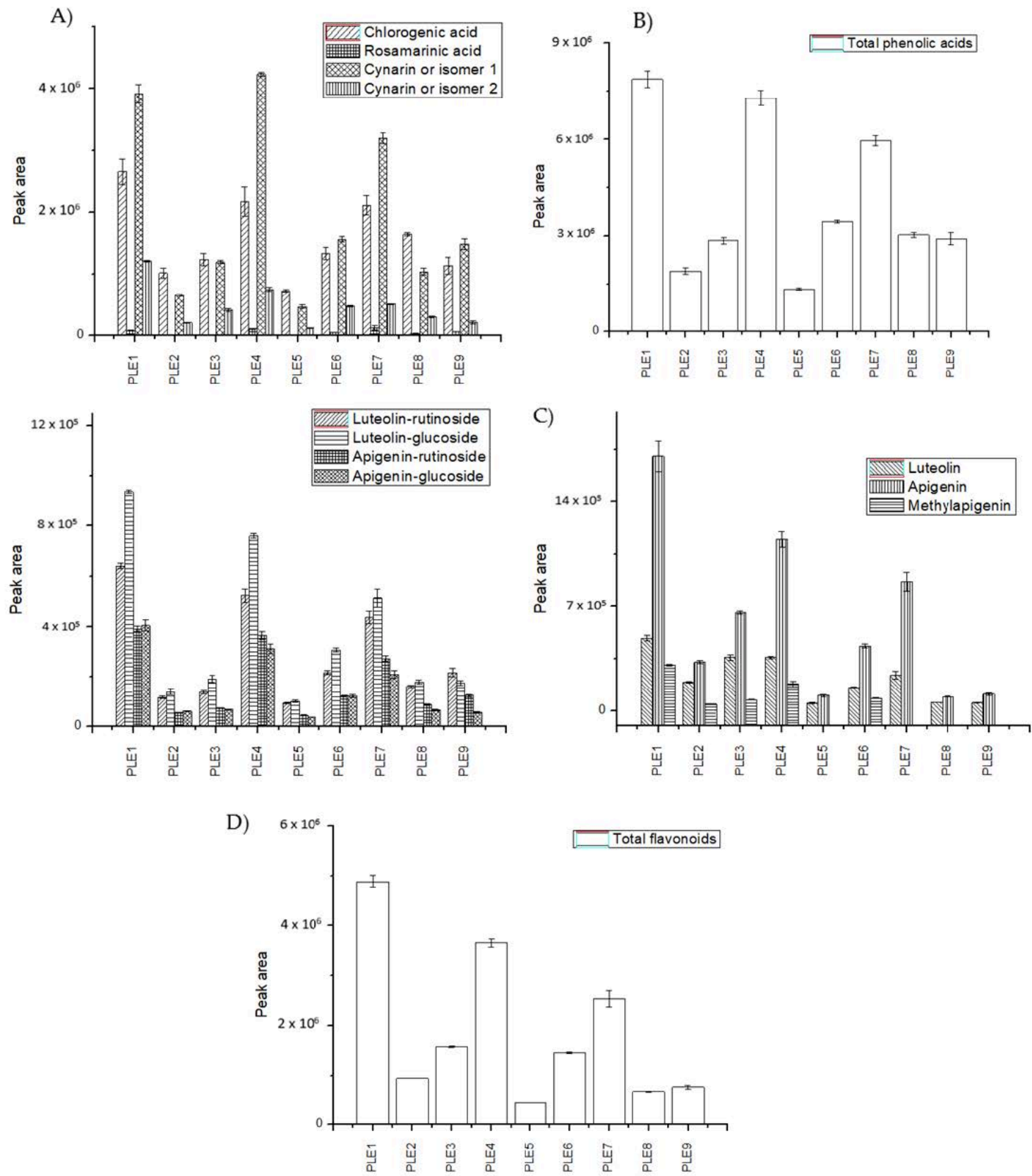

Figure 3. Abundance of phenolic compounds characterized in each C. scolymus PLE extracts by HPLC-ESI-TOF-MS: (A) individual phenolic acids, (B) total phenolic acids, (C) individual flavonoids, and (D) total flavonoids.

In regards to the total abundance of phenolic acids in the $C$. scolymus PLE extracts, it could be observed that PLE $1\left(120^{\circ} \mathrm{C}\right.$, EtOH $\left.100 \%\right)$, PLE $4\left(63{ }^{\circ} \mathrm{C}\right.$, EtOH $\left.85 \%\right)$, and PLE 7 
$\left(40{ }^{\circ} \mathrm{C}, \mathrm{EtOH} 50 \%\right)$ conditions showed the best recovery for this chemical sub-class. On the contrary, PLE $5\left(176{ }^{\circ} \mathrm{C}, \mathrm{EtOH} 15 \%\right)$ and PLE $2\left(176{ }^{\circ} \mathrm{C}, \mathrm{EtOH} 85 \%\right)$ present the worst extraction recoveries for this kind of substances. In light of these data, it can be concluded that higher percentages of ethanol in aqueous mixtures and moderate to high extraction temperature enhances the extraction of these compounds. On the contrary, very high temperatures, such as in PLE 5 and PLE 2, seem to act to the detriment of the extraction of phenolic acids.

Additionally, the individual behavior of phenolic acids was also monitored. Chlorogenic acid was extracted in greater abundance by PLE 1 condition (with the highest percentage of ethanol, $100 \%)$, followed by PLE $4\left(63{ }^{\circ} \mathrm{C}\right.$, EtOH $\left.85 \%\right)$ and PLE $7\left(40{ }^{\circ} \mathrm{C}\right.$, EtOH $50 \%$ ) experiments, which presented similar abundances. In the case of rosamarinic acid, the best extraction conditions were PLE 7 and PLE 4. Both experiments were performed with low-intermediate temperatures and medium-high percentages of ethanol. In fact, higher temperatures such as the applied in PLE $5\left(176^{\circ} \mathrm{C}, \mathrm{EtOH} 15 \%\right)$ recovered this compound in very low amount or could not extract rosamarinic acid from artichoke by-products, as in PLE $2\left(176{ }^{\circ} \mathrm{C}, \mathrm{EtOH} 85 \%\right)$ and PLE $3\left(200^{\circ} \mathrm{C}, \mathrm{EtOH} 50 \%\right)$. Finally, within the family of phenolic acids, cynarin isomers showed different behavior over the tested extraction conditions. PLE 1 run $\left(120^{\circ} \mathrm{C}, \mathrm{EtOH} 100 \%\right)$ reported a high value of cynarin isomer 1 peak area, while cynarin isomer 2 was not recovered in abundance. The same phenomena could be described for PLE $4\left(63{ }^{\circ} \mathrm{C}\right.$, EtOH $\left.85 \%\right)$ and PLE $7\left(40{ }^{\circ} \mathrm{C}\right.$, EtOH $\left.50 \%\right)$.

On the other hand, the analysis of the total abundance of flavonoids in the artichoke extracts indicated that PLE $1\left(120^{\circ} \mathrm{C}, \mathrm{EtOH} 100 \%\right)$ was the best condition, followed by PLE $4\left(63{ }^{\circ} \mathrm{C}, \mathrm{EtOH} 85 \%\right)$ and PLE $7\left(40{ }^{\circ} \mathrm{C}, \mathrm{EtOH} 50 \%\right)$. All these runs applied intermediate conditions within the range of temperature and percentage of ethanol as solvent combinations. On the contrary, the conditions PLE $2\left(176^{\circ} \mathrm{C}\right.$, EtOH $\left.85 \%\right)$, PLE $5\left(176{ }^{\circ} \mathrm{C}\right.$, EtOH $15 \%)$, PLE $8\left(120{ }^{\circ} \mathrm{C}, \mathrm{EtOH} 0 \%\right)$, and PLE $9\left(63^{\circ} \mathrm{C}, \mathrm{EtOH} 15 \%\right)$ reported a lower abundance with respect to the other PLE extracts.

Analyzing individual flavonoids, the highest abundance of glycoside structures was obtained under the conditions PLE $1\left(120^{\circ} \mathrm{C}, \mathrm{EtOH} 100 \%\right)$ and PLE $4\left(63^{\circ} \mathrm{C}, \mathrm{EtOH} 85 \%\right)$. On further consideration, aglycon flavonoids as luteolin and apigenin showed the same trend, being better extracted by the PLE 1 condition. The abundance of simple flavonoids, luteolin and apigenin, was not increased as extraction temperatures raised. This fact suggests that high temperatures did not generate the hydrolysis of glycoside forms over the extraction process (luteolin-glucoside, apigenin-glucoside, luteolin-rutinoside, and apigenin-rutinoside).

Taking into account all these results, a comparison of the extraction yield and phenolic compounds recovery in each experimental PLE run showed important differences. Although the high temperatures would improve the diffusivity of the solvent and break component-matrix interactions, which increase the solubility of the analytes and consequently enhance the extraction yields [27], it does not necessarily mean a greater recovery of phenolic compounds. This fact seems to occur with artichoke by-products, which could be related to different factors. Indeed, an excessive increase in temperature is demonstrated to negatively affect the extraction of thermolabile compounds, such as phenolic compounds [26].

In addition to the possible thermal degradation of compounds, different combinations of solvent composition and temperature provide changes in the dielectric constant value, which is crucial for the extraction recovery of the phytochemicals from natural sources. In this way, special attention has to be paid to PLE 1 condition $\left(120^{\circ} \mathrm{C}, 100 \% \mathrm{EtOH}\right)$ with a dielectric constant value of 19. Despite this condition reported the lowest yield, the recovery of phenolic compounds was higher compared to other PLE conditions. This phenomenon has also been reported in other plant matrices extracted by PLE at the same conditions $\left(100 \% \mathrm{EtOH}\right.$ and $\left.120^{\circ} \mathrm{C}\right)$ [23].

Thereby, PLE 1 condition provided 2.6, 7.6, and 3.4 times higher recovery of phenolic acids, flavonoids, and total phenolic compounds than PLE $8\left(120^{\circ} \mathrm{C}\right.$, EtOH $0 \%$, dielectric 
constant 50.4), respectively. Analyzing individual phenolic compounds identified in both PLE conditions, significant differences could be observed concerning the abundance of all of them (see Table S2). A similar trend was observed when the yield and recovery of phytochemical compounds of PLE $6\left(120^{\circ} \mathrm{C}, \mathrm{EtOH} 50 \%\right.$, dielectric constant 34.7) were compared to those obtained for PLE $1\left(120^{\circ} \mathrm{C}, \mathrm{EtOH} 100 \%\right.$, dielectric constant 19.0). Thus, the yield obtained for PLE 6 is 5.4 times higher than for PLE 1. Nevertheless, PLE 1 condition showed 2.6 times higher phenolic recovery than PLE 6.

Nonetheless, $\mathrm{tt}$ is important to remark that at dielectric constant values higher than 19, minor differences were observed on the yield and recovery of phenolic compounds among the experimental conditions. Indeed, PLE 8 (dielectric constant value, 50.4) obtained an extraction yield 1.1 times higher than PLE 6 (dielectric constant value, 34.7). Moreover, PLE 6 had 1.1, 2.2, and 1.3 times higher recovery of phenolic acids, flavonoids, and total phenolic compounds than PLE 8, respectively, significant differences among all the characterized phenolic compounds were found for PLE 8 and PLE 6, except for chlorogenic and rosamarinic acids (Table S2).

Therefore, similar differences on the yield and phytochemical recovery were also observed for PLE conditions where the same temperature was applied in combination with different percentages of ethanol, which consequently provides different values of dielectric constants. Some examples are: (a) temperature of $63^{\circ} \mathrm{C}$ combined with $15 \%$ of ethanol (PLE 9, dielectric constant value 59.1) or $85 \%$ of ethanol (PLE 4, dielectric constant 31) and (b) extractions at $176^{\circ} \mathrm{C}$ using $15 \%$ EtOH (PLE 5, dielectric constant 33.4) or 85\% EtOH (PLE 2, dielectric constant 21.6). These results pointed out that at the same working temperature, the recovery of phenolic compounds is improved when the solvent composition $(\% \mathrm{EtOH})$ provides the lowest value of dielectric constant.

Nevertheless, despite this focus in the targeted extraction of individual compounds provided by concrete PLE parameters, the total extraction yield should be considered if the main purpose is to obtain the maximum quantity of extract with a particular compound.

\section{Conclusions}

In the present work, the efficiency of PLE extraction for the recovery of phytochemicals from artichoke by-products was studied. The proposed extraction system by PLE obtained 9 extracts under different extraction conditions delimited by the technical limits of the PLE extractor. The analytical characterization of these extracts allowed the detection of 23 compounds, most of them were phenolic and other polar bioactive compounds previously identified in artichoke samples. The individual phenolic compounds recovery through the different PLE extraction conditions was estimated by considering the peak area of each compound in the chromatogram (three replicates), which permits a comparison of the same compound between extracts. This information could establish the best extraction condition for each compound or family. The best PLE parameters, for both phenolic acids and flavonoids, consist in high percentages of ethanol and medium-high temperatures. In addition, it should be pointed into light that at the same temperature, the recovery of individual phenolic compounds is improved when the solvent composition provides the lowest value of dielectric constant.

Supplementary Materials: The following are available online at https:/ / www.mdpi.com/article/10 .3390/app11093788/s1, Table S1: Peak areas of the identified compounds in C. scolymus pressurized liquid extraction (PLE), extracts expressed as mean \pm standard deviation of the three analyses replicates. Table S2: Statistical data of the PLE extraction conditions for individual phenolic compounds.

Author Contributions: Conceptualization, J.L.-S. and I.B.-L.; methodology, J.L.-S. and R.G.-M.; software, L.L.-S.; validation, J.L.-S., I.B.-L. and A.S.-C.; formal analysis, L.L.-S.; investigation, L.L.-S., P.G.-G. and D.Q.; data curation, L.L.-S.; writing-original draft preparation, L.L.-S.; writing-review and editing, J.L.-S. and I.B.-L.; visualization, R.G.-M.; supervision, J.L.-S., A.S.-C. and R.G.-M. All authors have read and agreed to the published version of the manuscript.

Funding: This research received no external funding. 
Institutional Review Board Statement: Not applicable.

Informed Consent Statement: Not applicable.

Data Availability Statement: All the data generated by this research have been included in the article. For any assistance it is possible to contact with the corresponding author.

Conflicts of Interest: The authors declare no conflict of interest.

\section{References}

1. Shirahigue, L.D.; Ceccato-Antonini, S.R. Agro-industrial wastes as sources of bioactive compounds for food and fermentation industries. Cienc. Rural 2020, 50, 50. [CrossRef]

2. Muñoz-Jauregui, A.M.; Ramos-Escudero, F. Componentes fenólicos de la dieta y sus propiedades biomedicinales-Phenolics compounds of the diet and his biomedicinal properties. Horiz. Méd. 2007, 7, 23-38.

3. Bataglion, G.A.; Da Silva, F.M.A.; Eberlin, M.N.; Koolen, H.H.F. Determination of the phenolic composition from Brazilian tropical fruits by UHPLC-MS/MS. Food Chem. 2015, 180, 280-287. [CrossRef]

4. Bataglion, G.A.; Da Silva, F.M.A.; Eberlin, M.N.; Koolen, H.H.F. Simultaneous quantification of phenolic compounds in buriti fruit (Mauritia flexuosa L.f.) by ultra-high performance liquid chromatography coupled to tandem mass spectrometry. Food Res. Int. 2014, 66, 396-400. [CrossRef]

5. Mármol, I.; Quero, J.; Jiménez-Moreno, N.; Rodríguez-Yoldi, M.J.; Ancín-Azpilicueta, C. A systematic review of the potential uses of pine bark in food industry and health care. Trends Food Sci. Technol. 2019, 88, 558-566. [CrossRef]

6. Cruzado, M.; Cedrón, J. Nutracéuticos, alimentos funcionales y su producción. Rev. Química PUCP 2012, 2, 33-36.

7. Sonnante, G.; Pignone, D.; Hammer, K. The Domestication of Artichoke and Cardoon: From Roman Times to the Genomic Age. Ann. Bot. 2007, 100, 1095-1100. [CrossRef] [PubMed]

8. Abu-Reidah, I.M.; Arraez-Roman, D.; Segura-Carretero, A.; Fernandez-Gutierrez, A. Extensive characterisation of bioactive phenolic constituents from globe artichoke (Cynara scolymus L.) by HPLC-DAD-ESI-QTOF-MS. Food Chem. 2013, 141, $2269-2277$. [CrossRef]

9. Lattanzio, V.; Kroon, P.A.; Linsalata, V.; Cardinali, A. Globe artichoke: A functional food and source of nutraceutical ingredients. J. Funct. Foods 2009, 1, 131-144. [CrossRef]

10. El-Mesallamy, A.M.D.; Abdel-Hamid, N.; Srour, L.; Hussein, S.A.M. Identification of polyphenolic compounds and hepatoprotective activity of artichoke (Cynara scolymus L.) edible part extracts in rats. Egypt. J. Chem. 2020, 63, 2273-2285.

11. Sanchez-Rabaneda, F.; Jauregui, O.; Lamuela-Raventos, R.M. Identification of phenolic compounds in artichoke waste by highperformance liquid chromatography-Tandem mass spectrometry. J. Chromatogr. A 2003, 1008, 57-72. [CrossRef]

12. Pandino, G.; Lombardo, S.; Mauromicale, G. Globe artichoke leaves and floral stems as a source of bioactive compounds. Ind. Crop. Prod. 2013, 44, 44-49. [CrossRef]

13. Orlovskaya, T.V.; Luneva, I.L.; Chelombit'Ko, V.A. Chemical composition of Cynara scolymus leaves. Chem. Nat. Compd. 2007, 43, 239-240. [CrossRef]

14. Shallan, M.A.; Ali, M.A.; Meshrf, W.A.; Marrez, D.A. In vitro antimicrobial, antioxidant and anticancer activities of globe artichoke (Cynara cardunculus var. scolymus L.) bracts and receptacles ethanolic extract. Biocatal. Agric. Biotechnol. 2020, $29,101774$. [CrossRef]

15. Kukić, J.; Popović, V.; Petrović, S.; Mucaji, P.; Ćirić, A.; Stojković, D.; Soković, M. Antioxidant and antimicrobial activity of Cynara cardunculus extracts. Food Chem. 2008, 107, 861-868. [CrossRef]

16. Aguilera, Y.; Martin-Cabrejas, M.A.; Gonzalez de Mejia, E. Phenolic compounds in fruits and beverages consumed as part of the Mediterranean diet: Their role in prevention of chronic diseases. Phytochem. Rev. 2016, 15, 405-423. [CrossRef]

17. Shen, Q.; Dai, Z.; Lu, Y. Rapid determination of caffeoylquinic acid derivatives in Cynara scolymus L. by ultra-fast liquid chromatography/tandem mass spectrometry based on a fused core C18 column. J. Sep. Sci. 2010, 33, 3152-3158. [CrossRef]

18. Rejeb, I.B.; Dhen, N.; Gargouri, M.; Boulila, A. Chemical Composition, Antioxidant Potential and Enzymes Inhibitory Properties of Globe Artichoke By-Products. Chem. Biodivers. 2020, 17, e2000073. [CrossRef]

19. Lozano-Sánchez, J.; Castro-Puyana, M.; Mendiola, J.A.; Segura-Carretero, A.; Cifuentes, A.; Ibáñez, E. Recovering bioactive compounds from olive oil filter cake by advanced extraction techniques. Int. J. Mol. Sci. 2014, 15, 16270-16283. [CrossRef]

20. Gonçalves, E.C.B.A.; Lozano-Sanchez, J.; Gomes, S.; Ferreira, M.S.L.; Cameron, L.C.; Segura-Carretero, A. Byproduct Generated During the Elaboration Process of Isotonic Beverage as a Natural Source of Bioactive Compounds. J. Food Sci. 2018, 83, $2478-2488$. [CrossRef]

21. Yang, M.; Ma, Y.; Wang, Z.; Khan, A.; Zhou, W.; Zhao, T.; Cao, J.; Cheng, G.; Cai, S. Phenolic constituents, antioxidant and cytoprotective activities of crude extract and fractions from cultivated artichoke inflorescence. Ind. Crop. Prod. 2020, 143, 111433. [CrossRef]

22. Palermo, M.; Colla, G.; Barbieri, G.; Fogliano, V. Polyphenol metabolite profile of artichoke is modulated by agronomical practices and cooking method. J. Agric. Food Chem. 2013, 61, 7960-7968. [CrossRef]

23. Nastić, N.; Borrás-Linares, I.; Lozano-Sánchez, J.; Švarc-Gajić, J.; Segura-Carretero, A. Optimization of the extraction of phytochemicals from black mulberry (Morus nigra L.) leaves. J. Ind. Eng. Chem. 2018, 68, 282-292. [CrossRef] 
24. Nastić, N.; Lozano-Sánchez, J.; Borrás-Linares, I.; Švarc-Gajić, J.; Segura-Carretero, A. New technological approaches for recovering bioactive food constituents from sweet cherry (Prunus avium L.) stems. Phytochem. Anal. 2020, 31, 119-130. [CrossRef]

25. Nastić, N.; Borrás-Linares, I.; Lozano-Sánchez, J.; Švarc-Gajić, J.; Segura-Carretero, A. Comparative Assessment of Phytochemical Profiles of Comfrey (Symphytum officinale L.) Root Extracts Obtained by Different Extraction Techniques. Molecules 2020, $25,837$. [CrossRef]

26. Figueroa, J.G.; Borrás-Linares, I.; Lozano-Sánchez, J.; Quirantes-Piné, R.; Segura-Carretero, A. Optimization of drying process and pressurized liquid extraction for recovery of bioactive compounds from avocado peel by-product. Electrophoresis 2018, 39, 1908-1916. [CrossRef]

27. Vazquez-Roig, P.; Picó, Y. Pressurized liquid extraction of organic contaminants in environmental and food samples. Trends Anal. Chem. 2015, 71, 55-64. [CrossRef] 